\title{
The Degree of Activation of Cardiac Muscle Depends on Muscle Length
}

\author{
Dilson J. E. Rassier
}

São Leopoldo, RS - Brazil

The Frank-Starling mechanism of the heart ${ }^{1-3}$ can be described as the relationship between force and length of cardiac muscle. With the advent of the cross bridge theory of muscle contraction ${ }^{4,5}$ and Gordon and collaborator's classical study ${ }^{6}$ describing the fitting of this theory to the force-length relationship in skeletal muscle, several investigators started to study this relationship in cardiac muscle.

The force-length relation in cardiac muscle is observed in a small variety of sarcomere lengths, between approximately $1.8 \mu \mathrm{m}$ and $2.3 \mu \mathrm{m}$. This region corresponds to the ascending limb of the force-length relation of skeletal-muscle ${ }^{6}$. The force levels of the myocardium vary from zero at $1.8 \mu \mathrm{m}$ to maximal force values at $2.3 \mu \mathrm{m}$. This large variation in force results in a very sleep force-length relation, especially when compared with this relation in skeletal muscle (fig. 1). To get an idea, when the tension developed by the myocardium at different sarcomere lengths is normalized in relation to its maximal force $\left(\mathrm{F}_{\text {max }}\right)$ at the point where maximal length $\left(\mathrm{L}_{\max }\right)$ occurs, the developed tension is approximately $10-15 \%$ when the myocardium is measured at $80 \% \mathrm{~L}_{\max }$. Yet in skeletal muscle, normalized force is approximately $80-85 \%$ of $\mathrm{F}_{\max }{ }^{7}$ under the same conditions (fig.1).

This difference between skeletal and cardiac muscle shows that the force-length relationship in the myocardium are not a simple function of the degree of superposition of actin and myosin filaments. Because their lengths are similar in both muscles, other factors must be involved in the muscle force-length relationship. During recent years, this difference has been attributed to the dependence of muscle activation on sarcomere length ${ }^{8}$.

Muscle activation has been used collectively in the literature to refer to various processes able to initiate muscle contraction, modifying the muscle state from "inactive" to "active". Thus, muscle activation has been associated with the frequency of muscle stimulation or membrane action potentials with intracellular $\mathrm{Ca}^{2+}$ concentration $\left[\mathrm{Ca}^{2+}\right]_{i}$, or the occupation of the protein troponin $\mathrm{C}(\mathrm{TnC})$ by $\mathrm{Ca}^{2+}$. In this article, the term muscle contraction will be utilized to

Universidade do Vale do Rio dos Sinos - Unisinos

Mailing address: Dilson J. E. Rassier - UNISINOS - Centro de Ciências da Saúde (02) - Av. Unisinos, 950 - 93022-000 - São Leopoldo, RS - Brasil describe the proportion of TnC associated with $\mathrm{Ca}^{2+}$. The association $\mathrm{TnC} / \mathrm{Ca}^{2+}$ represents a fundamental event in muscle contraction; therefore, the sensitivity of $\mathrm{TnC}$ to $\mathrm{Ca}^{2+}$ will be discussed in greater detail. This choice, furthermore, comes from studies shewing that myocardial force changes due to muscle length are unrelated to $\left[\mathrm{Ca}^{2+}\right]_{i}{ }^{9,10}$.

The present article contains a review of studies related to the dependence of force and, more importantly, of the process of myocardial muscle activation on muscle length. In particular, the article intends to investigate mechanisms responsible for the dependence of the sensitivity of filaments to $\mathrm{Ca}^{2+}$ on muscle length, as proposed in the literature.

Dependence of the sensitivity of filaments to $\mathrm{Ca}^{2+}$ on muscle length - Evidence that the activation of the myocardium is dependent on muscle length is found in studies demonstrating that inotropic interventions (for example, increased frequency of muscle stimulation) induce a displacement of the force-length relationship of the myocardium to the left. As a result, the slope of the force-muscle length relation resembles the relationship observed in skeletal muscle (fig.1) 7,11,12. $^{7}$.

Three main lines of research have been used for the evaluation of the dependence of the activation and sensitivity of the $\mathrm{Ca}^{2+}$ regulatory system on muscle length: 1) studies using intracellular $\mathrm{Ca}^{27}$ markers and rapid shortening of intact myocardial fibers; 2) studies using membrane-free fibers; 3 ) studies with isotope protein markers.

Studies measuring $\mathrm{Ca}^{2+}$ following abrupt fiber length changes are used to evaluate the affinity of $\mathrm{TnC}$ for $\mathrm{Ca}^{2+}$. In these studies, fluorescent $\mathrm{Ca}^{2+}$ marker compounds are introduced into cardiac cells, and, following adequate stimulation, they supply information about the intracellular quantity of $\mathrm{Ca}^{2+}$. These studies confirm that a reduction in the $\mathrm{TnC} / \mathrm{Ca}^{2+}$ affinity results in higher free $\mathrm{Ca}^{2+}$, because less $\mathrm{Ca}^{2+}$ is associated with TnC. This in turn would induce less muscle activation (according to the concept used in this article).

Different authors have demonstrated that an abrupt shortening of the intact cardiac muscle during the final stages of contraction results in decreased muscle tension, accompanied by increased levels of $\mathrm{Ca}^{2+}$. This observation suggests a decreased $\mathrm{TnC} / \mathrm{Ca}^{2+}$ association, i.e., the affinity of $\mathrm{TnC}$ for $\mathrm{Ca}^{2+}$ decreases when the muscle is shortened ${ }^{10,13-15}$. 


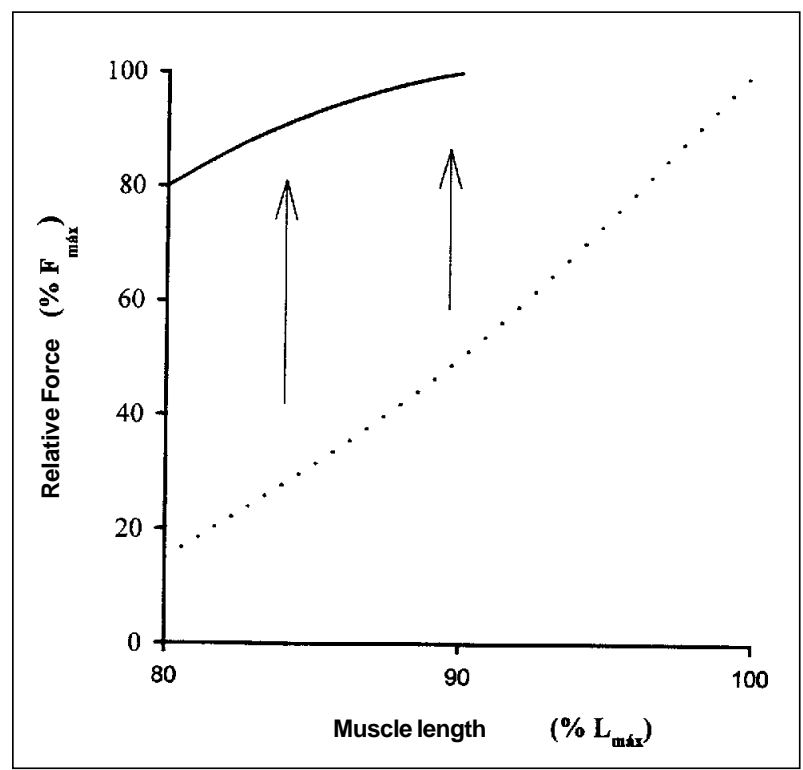

Fig. 1 - Schematic illustration of the force-length relationship of skeletal (solid line) and cardiac (broken line) muscle from $80 \mathrm{~L}_{\max }$ on. At this point, skeletal muscle produces $80-85 \%$ of its $\mathrm{F}_{\max }$, while cardiac muscle produces $10-15 \%$. At $90 \% \mathrm{~L}_{\max }$, skeletal muscle produces force close to $\mathrm{F}_{\max }$, while cardiac muscle produces $50 \% \mathrm{~F}_{\max }$. This is represented by an increased slope of the ascending limb of the force/length relationship in myocardial muscle (the region of normal operation of the myocardium) when compared with skeletal muscle.

Studies using membrane-free fibers analyze myocardial cells without the sarcolema enveloping the proteins responsible for muscle contraction. In this type of preparation, muscle contraction is initiated by the addition of $\mathrm{Ca}^{2+}$ to fibers kept in a liquid medium that also contains substances required to maintain the viability of the experiments, e.g., glucose. In this way, the investigator, by changing extracelular $\mathrm{Ca}^{2+}$ concentration, is able to establish force $/ \mathrm{Ca}^{2+}$ relationships under different conditions (fig. 2) and can control the activation induced by $\mathrm{Ca}^{2+}$.

The relationship force/ $\mathrm{Ca}^{2+}$ is extremely efficient for the study of cardiac muscle because it permits the investigation of the sensitivity of the regulatory system to $\mathrm{Ca}^{2+}$. According to this relationship, an increase in $\mathrm{Ca}^{2+}$ is associated with an increase in the force developed by the myocardium up to a given plateau. If the amount of $\mathrm{Ca}^{2+}$ necessary to produce a given force is decreased, the force/ $\mathrm{Ca}^{2+}$ relation is displaced towards the left (fig. 2), and the sensitivity of the system to $\mathrm{Ca}^{2+}$ increases.

In this context, it has been demonstrated that when the response is evaluated in long of sarcomeres, the amount of $\mathrm{Ca}^{2+}$ required to obtain a given force is decreased ${ }^{16,17}$. For example, in one of these studies, Hibberd and Jewell ${ }^{16}$ demonstrated that the amount of $\mathrm{Ca}^{2+}$ necessary for the force to reach $50 \%$ of $\mathrm{F}_{\text {max }}$ in a sarcomere set to a length of $\sim 2.5 \mu \mathrm{m}$ was significantly smaller than when the sarcomere was set to a length of $\sim 1.9 \mu \mathrm{m}$. In agreement with these results, Kentish et al ${ }^{17}$ demonstrated that each increase in sarcomere length was followed by an increase in muscle force running parallel to a slight shift to the left of the force/ $\mathrm{Ca}^{2+}$ relationship, signifying that a lesser amount of $\mathrm{Ca}^{2+}$ was necessary for the production of the same force.
Finally, some studies use specific isotope markers to analyze the degree of the association $\mathrm{TnC} / \mathrm{Ca}^{2+}$ and to relate it to muscle length ${ }^{18,19}$. These isotopes bind to specific TnC protein molecules, supplying information about the degree of the $\mathrm{TnC} / \mathrm{Ca}^{2+}$ association. In one of these studies ${ }^{19}$, the authors, using membrane-free bovine ventricle fibers tagged with these isotopes, demonstrated a strong association of $\mathrm{Ca}^{2+}$ to TnC during force generation. However, this association was directly related to muscle length; a reduction was observed in shorter sarcomeres. These results agree with previously cited studies in which the dependence of muscle length on $\mathrm{Ca}^{2+}$ sensitivity is related to $\mathrm{TnC}$.

The major question to be answered is: how does $\mathrm{TnC}$, a protein subunit associated with the binding of $\mathrm{Ca}^{2+}$ and $\mathrm{Mg}^{2+}$, receive information regarding structural changes in muscle length? To answer this question, different lines of investigation and hypotheses are presently under investigation. Some authors suggest that $\mathrm{TnC}$ itself might be the sensor of changes in muscle length ${ }^{20-22}$. This hypothesis is based on molecular differences between $\mathrm{TnC}$ of cardiac and skeletal muscle, which might be associated with the difference in the force-length relationship in both muscles. However, several studies have refuted this hypothesis ${ }^{23,24}$. In one of them, Moss et $\mathrm{al}^{23}$ characterized the relation between force produced and activation induced by $\mathrm{Ca}^{2+}$, at sarcomere lengths of $2.32 \mu \mathrm{m}$ and $1.87 \mu \mathrm{m}$ in membrane-free rabbit skeletal muscle fibers. Measurements were performed prior to and following substitution of TnC by cardiac muscle $\mathrm{TnC}$ to determine whether this was the main reason for the differences in force-length relationships of skeletal and cardiac muscle. Following a $>95 \%$ substitution of skeletal muscle TnC by cardiac muscle TnC, no significant changes in

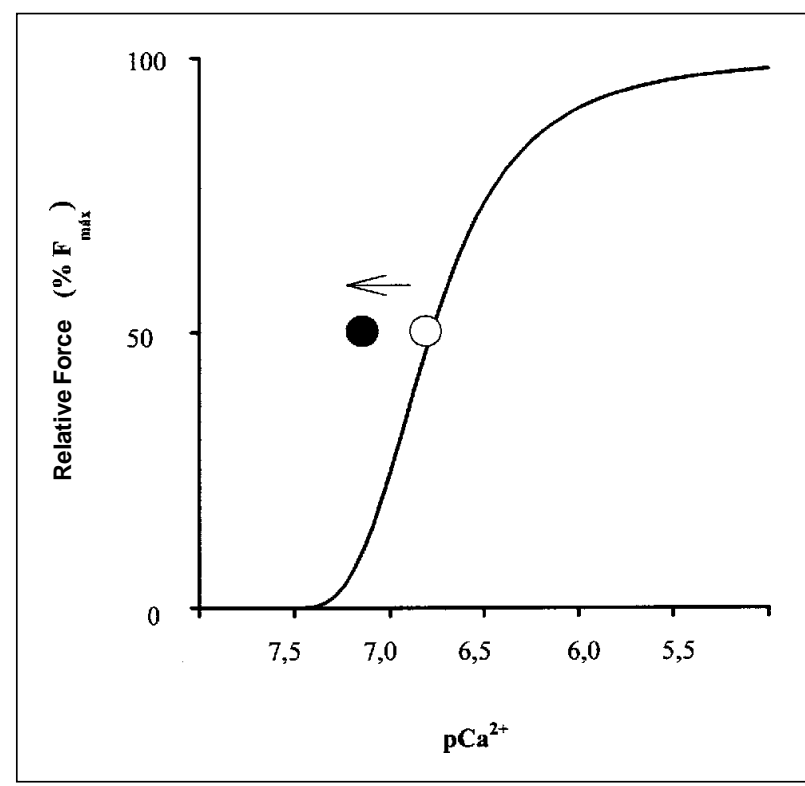

Fig. 2 - The force/Ca ${ }^{2+}$ relationship. $\left[\mathrm{Ca}^{2+}\right]$ is represented by p $\mathrm{Ca}^{2+}=\left(-\log _{10}\left[\mathrm{Ca}^{2+}\right]\right)$ The figure demonstrates that the amount of $\mathrm{Ca}^{2+}$ required for the production of force is decreased when the force/p $\mathrm{Ca}^{2+}$ relationship is displaced to the left (arrow directed from the empty circle to the full circle). This displacement is an indication of an increased sensitivity of the muscle system to $\mathrm{Ca}^{2+}$. 
$\mathrm{Ca}^{2+}$ sensitivity at the investigated lengths were observed. Therefore, TnC is not the major mechanism responsible for the dependence of the sensitivity of the muscle system on muscle length.

The hypothesis that is being successfully tested is that the association of cross bridges of myosin with actin and consequent force generation is responsible for the dependence of the degree of activation on muscle length ${ }^{18,19,25-29}$. The work and justification related to this hypothesis are presented below.

Force-length relationship of cardiac muscle and the association of cross bridges with actin - When cardiac muscle is lengthened at the ascending limb of the force-length relationship, an increased superposition of actin and myosin filaments takes place. This leads to an increased probability of interaction between cross bridges and actin, and consequently increased force generation. Strong lines of evidence exist in favor of a system in which this association increases sensitivity to $\mathrm{Ca}^{2+}$ of the system regulating force and, consequently, muscle activation.

This hypothesis has been tested in detail in the elegant studies of Fuchs et al ${ }^{18,19,26,27}$. Hofmann and Fuchs ${ }^{18}$ measured $\mathrm{TnC} / \mathrm{Ca}^{2+}$ association in membrane-free cardiac fibers using isotopes, as previously explained. As expected, results confirmed that $\mathrm{TnC} / \mathrm{Ca}^{2+}$ association depends on muscle length over the $1.7 \mu \mathrm{m}$ to $2.4 \mu \mathrm{m}$ range. In some experiments, the authors used a substance similar to phosphate $\left(\mathrm{P}_{\mathrm{i}}\right)$, sodium vanadate $\left(\mathrm{V}_{\mathrm{i}}\right)$, which acts as an ATPase enzyme, depressing the interaction of cross bridges with actin, forming a stable myosin $\bullet \mathrm{ADP} \bullet \mathrm{V}_{\mathrm{i}}$ complex. When $\mathrm{V}_{\mathrm{i}}$ was used, the relationship between $\mathrm{TnC} / \mathrm{Ca}^{2+}$ and sarcomere length was depressed, and the degree of muscle activation was not dependent on sarcomere length. Therefore, the dependence of the affinity of $\mathrm{Ca}^{2+}$ to TnC on muscle length would in reality be dependent of the number of cross bridges associated with actin.

Other evidence of the association of cross bridges with the affinity of $\mathrm{TnC}$ to $\mathrm{Ca}^{2+}$ is provided by the study of Saeky et $\mathrm{al}^{30}$, who used intact cardiac muscle fibers. In this work, fibers were injected with $\mathrm{Ca}^{2+}$ markers to perform rapid muscular shortening maneuvers, as already explained. In one set of experiments, extra $\mathrm{Ca}^{2+}$ was not detected when the fiber was shortened starting from a relaxed muscle state (without force production). In another group of experiments, the cycle of cross bridges was blocked by a specific chemical substance (2,3 butaneodione monoxime). It was noted that, changes in muscle length did not result in the appearance of extra $\mathrm{Ca}^{2+}$ in the intracellular space, even though force had decreased to a considerable extent. In other words, when the association between cross bridges and actin was blocked by a state of muscle relaxation or by a specific chemical substance, the association between $\mathrm{TnC} /$ $\mathrm{Ca}^{2+}$ did not depend on muscle length.

This leads to the conclusion that the increased sensitivity of the $\mathrm{Ca}^{2+}$ regulatory system induced by an increase in sarcomere length is related to an increased number of actin-associated cross bridges, both in membrane-free cardiac fibers and in cardiac fibers with intact membranes.

Cross bridges and regulation of troponin C activity Although association of cross bridges, force, and sensitivity of $\mathrm{TnC}$ to $\mathrm{Ca}^{2+}$ are related events, need exists to study the nature of these relationships. In other words, how does the association of crossed bridges of myosin with actin increase the affinity of TnC to $\mathrm{Ca}^{2+}$ and, consequently, the sensitivity of the muscle system to $\mathrm{Ca}^{2+}$ ? Studies in which TnC was tagged with fluorescent probes by substitution of specific molecules at some of its regulatory domains furnish some evidence on this issue ${ }^{31-33}$.

Hannon et al ${ }^{33}$ used cardiac TnC tagged with fluorescent probes, to furnish specific information concerning the structure of $\mathrm{TnC}$ resulting from its association with $\mathrm{Ca}^{2+}$. The authors measured sensitivity of responses to $\mathrm{Ca}^{2+}$ of the muscle system related to the association of cross bridges to link them to alterations of the structure of TnC. They observed that the association of cross bridges with actin caused conformation changes in $\mathrm{TnC}$, and that this alteration was accompanied by an increased sensitivity of the muscle system to $\mathrm{Ca}^{2+}$.

Along the same line of investigation, Liou and Fuchs ${ }^{31}$ tagged two TnC residues in bovine cardiac fibers with reactive compounds. By measuring the fluorescent signals of the compounds, they observed that cross bridges "in rigor" and cyclic cross bridges had different effects on the conformation of TnC, suggesting that the mechanisms by which cross bridges affect TnC involve molecular configuration.

These two studies offer an explanation for the mechanism responsible for the dependence of $\mathrm{Ca}^{2+}$ sensitivity on muscle length, by stating that an increase in muscle length induces alterations in the molecular conformation of TnC, resulting in an increase in its affinity for $\mathrm{Ca}^{2+}$.

Evidence for other mechanisms responsible for the dependence on muscle length of myocardial activation Although evidence pointing to mechanisms involving cross bridges as the phenomenon responsible for the dependence of force and filament sensitivity to $\mathrm{Ca}^{2+}$ on muscle length, this hypothesis has one obvious difficulty: sensitivity to $\mathrm{Ca}^{2+}$ is increased in membrane-free cardiac fibers ${ }^{34}$ when these are lengthened in the descending limb of the force-length relation, a region where the potential for myosin-actin interactions is decreased.

The hypothesis provided in the literature is that besides the association of cross bridges, force and $\mathrm{TnC} /$ $\mathrm{Ca}^{2+}$ affinity, changes in sarcomere length per se are responsible for alterations in the muscle system sensitivity to $\mathrm{Ca}^{2+}$. Studies using X-ray diffraction have demonstrated that actin and myosin filaments are positioned closer when the muscle is lengthened and muscle volume remains unmodified $^{35,36}$. It is reasonable, therefore, to suppose that the probability of interactions between cross bridges and actin would be increased in this situation, where the distance for 
association decreases. This possibility of an increased interaction between the filaments would increase force at a given concentration of $\mathrm{Ca}^{2+}$ thus increasing the sensitivity of the muscle system to this cation.

Along this line of investigation, different authors have studied the effects of osmotic compression of myosin and actin filaments, using a high molecular weight polymer dextran T-5000, polyvinylpyrrolidone-40. This compound does not penetrate the space between the actin and myosin filaments and causes lateral approximation between them. Some authors ${ }^{26,37}$ observed that following the use of this substance, sensitivity to $\mathrm{Ca}^{2+}$ in cardiac muscle was significantly increased.

Wang and Fuchs ${ }^{26}$ specifically investigated the hypothesis that alterations in the space between myosin and actin filaments contribute to the dependence on muscle length of myocardial sensitivity to $\mathrm{Ca}^{2+}$. These authors studied simultaneously the effect of osmotic compression (Dextran
T-5000, 5 and $10 \%)$, sarcomere length $(1.7 \mu \mathrm{m}$ to $2.3 \mu \mathrm{m})$, and the degree of $\mathrm{TnC} / \mathrm{Ca}^{2+}$ association. The results are convincing: the use of $5 \%$ dextran on a membrane stabilized at a sarcomere length of $1.7 \mu \mathrm{m}$ resulted in a $13 \%$ reduction in the diameter of the muscle fiber, equivalent to the situation in which the sarcomere is lengthened to $2.3 \mu \mathrm{m}$. Most importantly, this intervention was accompanied by a significant increase in muscle sensitivity to $\mathrm{Ca}^{2+}$ [an alteration of $-0.25 \mathrm{pCa}^{2+}$ ] (fig. 2) and in the association $\mathrm{TnC} / \mathrm{Ca}^{2+}$ at activation levels between 6.0 and $5.0 \mathrm{pCa}^{2+}$.

Conclusion - The studies reviewed in this article suggest that the dependence of sensitivity to $\mathrm{Ca}^{2+}$ on muscle length is an associative result of the interaction of myosin cross bridges and actin, which induces alterations of the $\mathrm{TnC} / \mathrm{Ca}^{2+}$ affinity, and of changes in the space between the filaments, which increases the probability of myosin/actin interaction.

\section{References}

1. Frank O. Zur Dynamik des Heizmuskel. Zeitschrift Biologie 1885; 32: 370-447.

2. Patterson SW, Piper H, Starling EH. The regulation of the heart beat. J Physiol 1914; 48: 465-513.

3. Patterson SW, Starling EH. On the mechanical factors which determine the output of the ventricles. J Physiol 1914; 48: 357-79.

4. Huxley AF, Simmons RM. Proposed mechanisms of force generation in striated muscle. Nature 1971; 233: 538.

5. Huxley AF. Muscle structure and theories of contraction. Progr Biophys biophys Chem 1957; 7: 255-318.

6. Gordon AM, Huxley AF, Julian FJ. The variation in isometric tension with sarcomere length in vertebrate muscle fibres. J Physiol 1966; 184: 170-192.

7. Allen DG, Jewell BR, Murray JW. The contribution of activation processes to the length-tension relation in cardiac muscle. Nature 1974; 248: 606-07.

8. Allen DG, Kentish JC. The cellular basis of the length-tension relation in cardiac muscle. J Mol Cell Cardiol 1985; 17: 821-40.

9. Morgan JP, Blinks JR. Intracellular calcium transients in the cat papillary muscle. Can J Physiol Pharmacol 1982; 60: 524-8.

10. Allen DG, Kurihara S. The effects of muscle length on intracellular calcium transients in mammalian cardiac muscle. J Physiol 1982; 327: 79-94.

11. Lakatta EG, Jewell BR. Length-dependent activation: Its effects on the lengthtension relation in cat ventricular muscle. Circ Res 1977; 40: 251-7.

12. ter Keurs HEDJ, Rijnsburger WH, Van Heuninger R, Naglesmit MJ. Tension development and sarcomere length in rat cardiac trabeculae: Evidence of lengthdependent activation. Circ Res 1980; 46: 703-14.

13. Allen DG, Kentish JC. The effects of length changes on the myoplasmic calcium concentration in skinned ferret ventricular muscle. J Physiol 1985; 366: 67P.

14. Lab MJ, Allen DG, Orchard CH. The effects of shortening on myoplasmic calcium concentration and action potential in mammalian ventricular muscle. Circ Res 1984; 55: 825-9.

15. Housmans PK, Lee NK, Blinks JR. Active shortening retards the decline of the intracellular calcium transients in mammalian heart muscle. Science 1983; 221: 159-61.

16. Hibberd MG, Jewell BR. Calcium- and length- dependent force production in rat ventricular muscle. J Physiol 1982; 329: 527-40

17. Kentish JC, ter Keurs HEDJ, Ricciardi J, Bucx JJJ, Noble MIM. Comparison between the sarcomere length-force relations in intact and skinned trabeculae from rat right ventricule. Circ Res 1986; 8: 755-68.

18. Hofmann PA, Fuchs F. Effect of length and cross-bridge attachment on $\mathrm{Ca}^{2+}$ binding to cardiac troponin C. Am J Physiol 1987; 253: C90-C6.

19. Hofmann PA, Fuchs F. Bound calcium and force development in skinned cardiac muscle bundles: effect of sarcomere length. J Mol Cell Cardiol 1988; 20: 667-77.

20. Babu A, Scordilis S, Sonnenblick E, Gulati J. The control of myocardial con- traction with skeletal fast muscle troponin C. J Biol Chem 1987; 262 5815-22.

21. Babu A, Sonnenblick E, Gulati J. Molecular basis for the influence of muscle length on myocardial performance. Science 1988; 240: 74-6.

22. Gulati J, Sonnenblick E, Babu A. The role of troponin C in the length dependence of $\mathrm{Ca}^{2+}$-sensitivity force of mammalian skeletal and cardiac muscles. J Physiol 1990; 441: 305-24.

23. Moss RL, Nwoye LO, Greaser ML. Substitution of cardiac troponin C into rabbit muscle does not alter the length dependence of $\mathrm{Ca}^{2+}$ sensitivity of tension. J Physiol 1991; 440: 273-89.

24. McDonald KS, Field LJ, Parmacek MS, Soonpaa M, Leiden JM, Moss RL Length-dependence of $\mathrm{Ca}^{2+}$ sensitivity of tension in mouse cardiac myocytes expressing skeletal troponin C. J Physiol 1995; 483: 131-9.

25. BurkhoffD. Explaining load dependence of ventricular contractile properties with a model of excitation-contraction coupling. J Mol Cell Cardiol 1994; 26: 959-78.

26. Wang Y, Fuchs F. Length, force, and $\mathrm{Ca}^{2+}$-troponin $\mathrm{C}$ affinity in cardiac and slow skeletal muscle. Am J Physiol 1994; 266: C1077-C82.

27. Hofmann PA, Fuchs F. Evidence for a force-dependent component of calcium binding to cardiac troponin C. Am J Physiol 1987; 253: C541-C6.

28. Johnson JD, Charlton SC, Potter JD. A fluorescence stopped-flow analysis of $\mathrm{Ca}^{2+}$ exchange with troponin. J Biol Chem 1979; 254: 3497-502.

29. Kurihara S, Komukai K. Tension-dependent changes on the intracellular $\mathrm{Ca}^{2+}$ transients in ferret ventricular muscles. J Physiol 1995; 489: 617-25.

30. Saeky Y, Kurihara S, Hongo K, Tanaka E. Alterations in intracellular calcium and tension of activated ferret papillary muscle in response to step length changes. J Physiol 1993; 463: 291-306.

31. Liou Y,Fuchs F. Pyrene-labeled cardiac troponin C. Effects of $\mathrm{Ca}^{2+}$ on monomer and excimer fluorescence in solution and in myofibrils. Biophys J 1992; 61: 892-901.

32. Matsubara I, Maughan DW, Saeky Y, Yagi N. Cross-bridge movement in rat cardiac muscle as a function of calcium concentration. J Physiol 1989; 417: 555-65.

33. Hannon JD, Martyn DA, Gordon AM. Effects of cycling and rigor crossbridges on the conformation of cardiac troponin C. Circ Res 1992; 71: 984-91.

34. Fabiato A, Fabiato F. Myofilament-generated tension oscillations during partial calcium activation and activation dependence of the sarcomere length-tension relation of skinned cardiac cells. J Gen Physiol 1978; 72: 667-99.

35. Matsubara I, Elliot GF. X-ray diffraction studies on skinned single fibers of the frog skeletal muscle. J Mol Biol 1972; 72:657-669.

36. Rome E. Relaxation of glycerinated muscle: Low angle X-ray diffraction studies J Mol Biol 1972; 65: 331-45.

37. Harrison SM, Lammont C, Miller DJ. Hysteresis and length-dependence of calcium sensitivity in chemically skinned rat cardiac muscle. J Physiol 1988; 401: 115-43. 